


\section{Article Artículo Paper Factors que condicionen 3 l'experiència i els resultats escolars dels infants tutelats residents en CRAE. Revisió de la literatura}

\section{Marta Garcia}

Molsosa $^{1}$

\section{Resum}

L'article descriu la situació i les particularitats dels infants $\mathrm{i}$ adolescents en acolliment residencial a $\mathrm{Ca}-$ talunya dins el context escolar. Partint de les dades recollides recentment en el marc del projecte d'investigació europeu YiPPEE, s'exposen alguns factors que permeten comprendre la vulnerabilitat de la seva situació a partir de l'anàlisi de les aportacions de la investigació i literatura científica sobre les variables que incideixen en les elevades taxes de fracàs escolar que presenten. En l'article es suggereixen algunes línies d'investigació educativa per avançar en la lluita contra el fracàs escolar d'aquest col-lectiu, amb la voluntat de contribuir a situar aquesta problemàtica dins les prioritats del sistema de protecció i d'educació i generar alternatives a la realitat actual que permetin superar la situació de desavantatge social que pateixen aquests infants $\mathrm{i}$ adolescents $\mathrm{i}$ els obstacles i dificultats que es troben els seus itineraris educatius. Partint de la pre-

1. màster en educació inclusiva, Universitat de Vic. Educadora social en un CRAE. 
missa que l'educació formal hauria de ser, per a aquest col-lectiu, una gran oportunitat per al reeiximent personal i la participació social i posant de manifest que les dades i investigacions sobre la temàtica indiquen que encara queda molt camí per recórrer.

Paraules clau: fracàs escolar, acolliment residencial, resiliència, educació inclusiva.

\begin{abstract}
This article describes the situation and characteristics of children and young people in residential care in Catalonia within the school context. Starting from data collected recently in the framework of the European research project YiPPEE, the paper exposes and analyses some factors that allow us to understand the vulnerability of their situation according to the recent research on this field. This analysis suggests some educational research lines to move forward the struggle against the school failure of children in residential care. The aim of this article is to contribute to put this issue within the priorities of the education and protection system and generate alternatives to the current reality, to overcome the social disadvantage suffered by these children and the difficulties encountered by their educational pathways. Unlike the premise that formal education should be a great opportunity for personal achievement and social participation for these children, research on the subject indicate that much remains to do to reach it.
\end{abstract}

Key words: school failure, residential care, resilience, inclusive education. 


\section{Introducció}

Els infants i adolescents residents en Centres Residencials d'Acció Educativa (CRAE) són el col·lectiu amb un risc més elevat de fracàs escolar, presentant alhora els resultats acadèmics i els itineraris educatius més desavantatjosos. Les dades que hem pogut conèixer recentment gràcies al projecte de recerca europeu YiPPEE ${ }^{2}$ són alarmants: la taxa de fracàs escolar afecta a més de la meitat d'aquest col·lectiu i el seu accés a l'educació superior és molt minoritari (Jackson i Cameron, 2014). L'equip català del YiPPEE, liderat per la professora Carme Montserrat, ha posat de manifest que al nostre país gairebé dos terços d'aquests nois i noies no obtenen el graduat a quart d'ESO i el 65\% són orientats cap a Programes de Formació i Inserció (Montserrat, Casas, Casas, i Baena, 2013).

Per a aquests infants i adolescents, que parteixen d'una situació de desigualtat i vulnerabilitat social molt significativa, l'educació formal representa un factor protector clau i una oportunitat per al reeiximent personal i social. Al Regne Unit, primer país on es va publicar una investigació en aquests termes (Jackson i Martin, 1998), les dades mostraven que un èxit educatiu modest marcava grans diferències entre els joves extutelats. De tal manera que no tenir estudis representava per a ells grans probabilitats d'estar a l'atur, ser mares solteres en el cas de les noies, infractors o persones sense sostre i, per tant, de formar part dels sectors exclosos de la societat. Mentre que l'obtenció d'un graduat en estudis mitjans comportava tenir estadísticament moltes més probabilitats de viure de manera autònoma i reduïa més de deu vegades la probabilitat de viure processos d'exclusió.

En efecte, cada vegada tenim més evidències que en el context social actual la manca de formació bàsica té importants conseqüències negatives, no només en relació a les oportunitats laborals, sinó vinculades a totes les dimensions i oportunitats vitals i de benestar al llarg de la vida, com la salut física i mental i la participació en la vida política i cultural (Cebolla-Boado, Rad1, i Salazar, 2014; Fernández Enguita, Mena Martínez, i Riviere Gó-

2. Acrònim de Young People in Public Care: Pathways to Education in Europe. Aquesta investigació es va dur a terme entre el 2008 i 2010, en el marc del"VIIè programa marc" de la Comissió Europea, a Anglaterra, Dinamarca, Hongria, Suècia i Espanya. Concretament, en el cas espanyol, la recerca es va ubicar a Catalunya i va ser dirigida per l'Equip de Recerca sobre Infancia, Adolescència, Drets dels Infants i la seva Qualitat de Vida (ERIDIQV) de la Universitat de Girona. Les dades obtingudes es poden consultar a: http://www.udg. edu/tabid/19983/language/ca-ES/Default.aspx 
mez, 2010). A més, els llindars educatius mínims que permeten accedir al benestar són cada vegada més alts, situant-se actualment en l'educació secundària post-obligatòria i, especialment, en la universitària (Curran i Tarabini, 2013; Eurostat 2015).

Donada aquesta realitat, tant des de la recerca sobre educació i infância, com des d'instàncies polítiques, serveis tècnics i professionals que treballen en aquest àmbit, es fa especialment urgent preguntar-se, preocupar-se i ocupar-se de l'escolarització dels aproximadament 2.000 infants i adolescents residents en CRAE a Catalunya ${ }^{3}$, comprendre les particularitats de la seva situació educativa i el seu itinerari escolar i construir alternatives a la realitat actual ben fonamentades. Emmarcat dins aquest objectiu de posar a l'agenda política i de recerca la realitat d'aquests infants, tant com a residents al CRAE com també en tant que alumnes d'escoles i instituts, aquest article té dos propòsits: a) exposar l'estat de la qüestió d'aquesta problemàtica a Catalunya; i b) aportar algunes claus per a la seva anàlisi i comprensió amb la voluntat de posar les bases per actuar per a un major èxit educatiu d'aquest col·lectiu.

\section{Per què es dóna una major afectació del fracàs escolar entre els infants residents en CRAE? Els factors clau que assenyala la literatura científica.}

Si bé el fracàs escolar no és una situació exclusiva del col-lectiu d'infants tutelats, si que els afecta d'una manera més generalitzada i punyent que al conjunt de la població infantil i de la població tutelada en particular, mostrant unes xifres comparativament pitjors tant pel què fa als resultats acadèmics com a l'assistència i al comportament (Montserrat et al., 2013). Dades que constaten la tesi segons la qual el fracàs escolar no afecta a tothom per igual, sinó que hi ha una sèrie d'elements que n'augmenten el risc i fan que determinats col·lectius siguin més propensos a patir-lo (Fernández Enguita et al., 2010).

En el cas dels infants $\mathrm{i}$ adolescents residents en CRAE, podem explicar aquesta major incidència o risc de fracàs escolar a partir de tres variables: les seves característiques

3. Segons dades de DGAIA de 2013 ( «Mapa de Serveis Socials de Catalunya. Actualització de dades bàsiques 2014. Departament de Benestar Social i Família. Generalitat de Catalunya»). Aquesta xifra representa el 38\% dels infants tutelats i ha crescut en números absoluts els darrers deu anys. 
poblacionals i origen sociofamiliar; la seva trajectòria vital i les particularitats del context residencial on viuen; i la incapacitat dels sistemes d'educació formal i de benestar a l'hora de "compensar" la situació desavantatjosa en la qual es troben.

Pel què fa a les característiques poblacionals, cal tenir present que el "perfil" predominant del col-lectiu d'infants i adolescents acollits en centres a Catalunya té fortes coincidències amb la població amb més probabilitats de fracassar dins el sistema educatiu: nois, majors de 12 anys, provinents d'entorns sociofamiliars vulnerables, en moltes ocasions fills de minories ètniques o d'immigrants, amb un alt grau d'inestabilitat familiar i una afectació creixent de problemes de salut mental (Casas, 2012; Síndic de Greuges, 2009). En efecte, les principals recerques d'àmbit català i espanyol sobre fracàs escolar ens indiquen que, a l'hora d'explicar la distribució desigual d'aquest entre els diferents segments de població, prenen especial rellevància la classe social i nivell d'estudis de la família d'origen; l'edat i el sexe (essent els nois adolescents el col-lectiu amb més risc de fracàs); el grau d'inestabilitat en la vida familiar de l'alumne; i l'afectació de problemes psicoafectius i/o cognitius (Fernández Enguita et al., 2010).

La segona variable que cal considerar és la trajectòria vital dels infants i adolescents residents en CRAE, marcada per un triple desavantatge social lligat a la seva vida amb la família d'origen, l’ingrés i estada al centre i el procés de transició a la vida adulta (Jackson i Cameron, 2014). De tal manera que la seva escolarització no tan sols ve marcada pel perfil poblacional, el capital econòmic i cultural de la seva família d'origen i la càrrega vital i emocional adversa que sovint l'acompanya, sinó també pels processos d'internament i desinternament al CRAE i els desavantatges que representa viure en un context residencial que, en general i malgrat els esforços per apropar-lo als models familiars, és més restrictiu, té una orientació i un clima menys familiar i menys connexions amb la comunitat (Jones i Lansdverk, 2006).

En tercer lloc, si volem comprendre la situació educativa dels infants i adolescents residents en CRAE cal tenir present el paper que hi juguen els sistemes de benestar i educació. En efecte, les polítiques, estructura i organització d'ambdós sistemes, juntament amb la resta de nivells de responsabilitat - individual/familiar i institucional/professional tenen, en positiu i en negatiu, repercussions sobre el benestar i l'èxit escolar i educatiu dels infants en acolliment residencial (Jackson i Cameron, 2014). El sistema de protecció cata- 
là té importants limitacions a l'hora d'oferir la mesura més adequada a les particularitats i necessitats de cada cas i garantir que es compleix el principi de l'interès superior de l'infant (Casas, 2012; Funes, 2008). A la vegada, com analitzarem més endavant, dins el sistema educatiu es poden identificar certs elements interns amb impacte directe sobre el procés de construcció del fracàs escolar (Curran i Tarabini, 2013; Fernández Enguita et al., 2010; Tarabini, 2014).

D'aquestes tres variables, volem destacar la institucional i professional i la política com aquelles sobre les que podem incidir de manera més clara. Per això en el present article ens centrem en l'anàlisi de com les polítiques educatives i de benestar, els recursos, l’organització i la coordinació entre ambdós sistemes, el paper de l'escola i el treball dels centres residencials i dels professionals que hi treballen, entre altres, poden afectar, positiva o negativament, el procés de construcció del fracàs escolar i de quina manera es pot fer decantar la balança cap a la superació de dificultats i l'èxit educatiu.

\subsection{Factors institucionals. Les particularitats dels infants $i$ adolescents residents} en CRAE dins el context escolar.

La presència de dificultats en el context escolar dels infants $i$ adolescents residents en CRAE acostuma a precedir l'entrada al centre i podem relacionar-la amb les característiques del seu context familiar d'origen. Ara bé, a aquesta desigualtat de partida cal sumar-hi les particularitats i implicacions que té l'ingrés i vida a un centre residencial a nivell escolar i les condicions en què es produeix el seu procés d'emancipació quan arriben a la majoria d'edat.

L'ingrés a un CRAE implica el trencament de l'infant o adolescent amb el seu entorn familiar, social i escolar d'origen i el contacte entre aquesta antiga realitat i el nou context sol ser mínim, reduït al règim de visites amb la família biològica establert pels Equips d'Atenció a la Infancia i Adolescència (EAIA). Aquest trencament brusc amb la seva vida anterior a nivell de família, escola, amics, barri,... es dóna tant a nivell econòmic com cultural i axiològic. De tal manera que l'arribada a un centre suposa per l'infant l'entrada a un sistema estructural, cultural i simbòlic desconegut, sovint molt diferent -O inclús oposat- al del seu nucli familiar d'origen. La ubicació al centre requereix un procés d'adaptació i d'integració que està fortament mediatitzat per factors emocionals, afectius i 
identitaris, dels quals en destaquem els cinc més recurrents i rellevants segons la principal bibliografia sobre la temàtica.

En primer lloc, la vivència, expectatives i la manera de gestionar l'internament per part de la família d'origen (Torralba, 2006). En segon lloc, les limitacions per se que té el CRAE, com a institució, a l'hora d'actuar com a mesura substitutòria del context familiar i funcionar com un sistema referencial sòlid, flexible, segur, estable i compensatori a nivell emocional i afectiu. Principalment per la impossibilitat d'equiparar els professionals que hi treballen a la figura materna/paterna (Fernández, 2003; Palacios, 2003) i també per la tendència a l'augment de les places i la sobreocupació dels CRAE a Catalunya, que els allunya dels models "familiars" (Síndic de Greuges, 2009). En tercer 1loc, el desajust que sovint existeix en l'adequació de la mesura al pla individual i les necessitats de l'infant o adolescent (Fernández, Alvarez-Baz, i Bravo, 2003; Fernández i Fuertes, 2005). A Catalunya, el sistema de protecció ha convertit els CRAE en un "calaix de sastre" $i$ una "sala de (llarga) espera" per alguns infants pels quals no es troba una alternativa millor, ja sigui per falta de famílies d'acollida i/o de centres especialitzats per infants amb greus problemes de salut mental (Casas, 2012; Funes, 2008; Síndic de Greuges, 2009). En quart 1loc, la consideració del centre com a "lloc de pas", donat que per llei s'estableix com una mesura subsidiària i transitòria ${ }^{4}$, en condiciona l'organització i comporta que l'allargament de la mesura sigui viscut de manera negativa tant pels professionals com, especialment, pels infants i adolescents que hi resideixen, als quals se'ls pot traslladar aquesta sensació de provisionalitat permanent i generar-los falses expectatives de sortida a curt o mig termini. Finalment, com a cinquè i últim factor convé assenyalar que, a nivell emocional i afectiu, el procés d'adaptació al centre va lligat al fet que l'infant ha d'anar establint nous vincles a la vegada que inicia un procés de "reelaboració" o "eliminació" dels que tenia fins aleshores. Això significa: vincular-se a partir d'altres paràmetres i elaborar processos de dol. Vinculació que ve condicionada pel fet que, com hem apuntat, existeix una gran distància entre la figura materna/paterna i el cuidador professional i pel vincle primigeni que l'infant ha construït amb la seva mare i/o cuidador/a principal/s (Ainsworth i Bell, 1970; Barudy i Dantagnan, 2005; Bolwby, 1969).

4. Article 130.1 de la Llei 14/2010 d’infancia de Catalunya. 
Tots aquests factors poden comportar que en alguns casos el sentiment de pertinença al centre no acabi d'aflorar mai i es generi una situació de "desarrelament" permanent de l'infant, que se sent "fora de lloc" tant en el sí de la seva família com en la institució on resideix. A la vegada que pot comportar que la mesura sigui viscuda com un "càstig" immerescut i incomprensible i vagi acompanyada d'una gran incertesa de futur. Mentrestant, les recerques sobre la temàtica alerten que desenvolupar un sentit de pertinença és molt important per garantir l'estabilitat i èxit en l'emplaçament d'acollida, en aquest cas, els CRAE (Sinclair, Gibbs, i Wilson, 2004) i, a la vegada, afavorir l'èxit escolar (Jackson i Cameron, 2014; Montserrat, Casas, Malo, i Bertran, 2012).

A aquest procés de trencament, adaptació i (re)vinculació complex, cal afegir-hi el canvi de centre escolar que acostuma a anar-hi associat. En efecte, l'ingrés a un centre representa, en gairebé tot els casos, un canvi d'escola. Fet que incrementa la inestabilitat i discontinuïtat en les seves trajectòries escolars, sovint ja condicionada pels freqüents canvis de residència de la seva família d'origen abans de l'ingrés al CRAE. Recerques recents han comprovat que es produeix una millora significativa, tant a nivell comportamental com de resultats, a mesura que augmenten els anys que els infants porten escolartizats a la mateixa escola (Montserrat et al., 2012). Per la seva banda, les visites familiars, els canvis en la situació familiar i els processos de desinternament, sovint incerts i amb poques possibilitats de previsió en el temps, no coincideixen ni s'ajusten al calendari i horari escolar, la qual cosa augmenta la situació d'inestabilitat a l'escola i contribueix a engrandir les dificultats en la integració social i l'adquisició d'aprenentatges (Montserrat, Casas, i Baena, 2015; Montserrat et al., 2012).

Al mateix temps, viure a un centre té impacte directe sobre les possibilitats i processos d'integració social en tant que genera dinàmiques estigmatitzadores. Per una banda, una certa autopercepció de "ser diferents" per part dels infants que resideixen en CRAE i, per l'altra, "l'etiquetatge" per part de la comunitat escolar - alumnes, famílies, docents i altres professionals - (Martín, García, i Siverio, 2012; Torralba, 2006).

E1 fet de "sentir-se diferent" per part dels infants i adolescents de CRAE és una constant que s'ha observat en diferents investigacions (Fernández, 2003; Torralba, 2006). Aquestes diferències autopercebudes són viscudes de manera negativa, ja que els infants persegueixen la conformitat amb el grup d'iguals, especialment quan estan a l'etapa d'edu- 
cació primària (Dubet i Martuccelli, 1998). Això explica que la voluntat de tenir una identitat "normal" i l'aspiració de fugir de l'etiqueta de "tutelat" actuïn com a factors de protecció centrals i motors per la motivació, la determinació i l'esforç que implica obtenir cert èxit acadèmic (Jackson i Cameron, 2014; Montserrat et al., 2012; Montserrat, González, et al., 2010).

Per altra banda, en general existeix un fort desconeixement de la realitat dels CRAE per part dels membres de la comunitat escolar (Jackson i Cameron, 2014; Montserrat et al., 2012). Fet que contribueix a generar una sèrie de prejudicis vers els infants de CRAE i en condiciona les seves relacions socials i possibilitats d'inclusió. En efecte, s'ha observat que companys i mestres tendeixen a assignar una sèrie d'atributs negatius als infants que viuen en centres, tals com tenir males relacions amb els mestres, ser agressiu o voler cridar sempre l’atenció (Bravo i Del Valle, 2003; Martín et al., 2008).

Aquest doble procés d'estigmatització contribueix a explicar les dificultats que tenen els infants i adolescents de CRAE a l'hora d'establir relacions amb els iguals fora del centre (Bravo i Fernández, 2001, 2003; Martín, Muñoz, Rodríguez, i Pérez, 2008). Donat que l'escola és el context normalitzat - de vegades l'únic - en què es relacionen amb altres nens i nenes, els vincles que hi puguin establir juguen un paper especialment rellevant en el seu desenvolupament emocional, cognitiu i social (Martín et al., 2008).

Finalment, els centres presenten certes particularitats que els allunyen de "l'ideal familiar escolar" (Bourdieu, 1997), la qual cosa pot ser vista des d'una òptica negativa i viscuda com un problema per l'escola, i dificultar les dinàmiques de comunicació i participació escolars per part dels CRAE sabent que aquestes estan directament relacionades amb els resultats acadèmics (Collet-Sabé, Besalú, Feu, i Tort, 2014). Aquestes característiques diferencials són, per una banda, que el responsable de l'infant és una institució i, per l'altra, que l'interlocutor amb l'escola és un - o més - professionals. Així, les dinàmiques de comunicació, coordinació i participació vindran marcades pels criteris organitzatius i educatius del CRAE; per l'establiment d'una relació de professional a professional; per un canvi de referents constant - ja sigui per l'organització dels torns laborals, canvis en les tutories o per la jerarquia pròpia del centre -; i pel grau de disponibilitat i implicació personal de cada professional. 
Per acabar, un altre aspecte clau del desavantatge social dels infants i adolescents de CRAE en relació a l'àmbit escolar és el procés de transició a la vida adulta amb l'assoliment de la majoria d'edat. Aquest és viscut amb incertesa, pors i inseguretat, ja que va lligat al desinternament $\mathrm{i}$, per tant, a un nou canvi de context, la pèrdua de referents i un procés sense possibilitats de marxa enrere (Jackson i Cameron, 2014; Montserrat et al., 2012).

A nivell acadèmic el procés de transició a la vida adulta coincideix amb un moment de decisions fonamentals en l'àmbit educatiu: continuar o no continuar els estudis, optar per la formació professional o l'acadèmica,... Aquestes opcions, altament condicionants pel futur es prenen en un moment maduratiu - adolescència - $\mathrm{i}$ un context social - societat del coneixement, descrèdit de la institució escolar - en què es produeix la major "desvinculació” en relació a la institució escolar (Fernández Enguita et al., 2010). Junt amb aquest "desenganxament" generalitzat respecte l'escola, els adolescents i joves de classes populars tendeixen a infravalorar el valor instrumental de l'educació i relativitzar la seva importància en l'accés al mercat laboral i, per tant, a optar per la sortida del sistema educatiu (Fernández Enguita et al., 2010).

En el cas dels adolescents que resideixen en CRAE, a aquesta manca de valorització dels estudis cal afegir-hi la necessitat de ser autònoms als 18 anys i, per tant, d'integrar-se al mercat laboral quan més aviat millor. Aquesta situació revela una forta desigualtat si comparem les dades, segons les quals el 84,2\% de joves d'entre 20 i 24 anys continuen vivint amb els pares (Secretaria de Joventut, 2008). De tal manera que s'espera que els joves tutelats siguin independents molt abans que la resta de joves $i$ de manera ràpida $i$ comprimida.

A Catalunya, des de fa quinze anys, es compta amb el suport que dóna l'Àrea de Suport al Jove Tutelat i Extutelat (ASJTET) a nivell econòmic, d'habitatge, d'inserció laboral, d'acompanyament jurídic, i de seguiment i suport socioeducatiu. Ara bé, aquest servei no és accessible per a tots els joves, especialment aquells que presenten més dificultats, conductes més disruptives o problemes de salut mental (Síndic de Greuges, 2009). En conseqüència, molts dels joves extutelats - una tercera part -, al trobar-se sense alternatives, retornen amb la família d'origen sense necessitat ni garantia que les situacions adverses que van provocar l'internament s'hagin resolt (Sala, Jariot, Villalba, i Rodríguez, 2009). 
Tot plegat, fa que des dels CRAE es prioritzi l'orientació cap a programes d'inserció laboral enlloc d'encoratjar la continuïtat dels estudis més enllà de l'etapa obligatòria, amb la voluntat d'intentar garantir una mínima autonomia dels joves un cop surten del sistema de protecció (Jackson i Cameron, 2014; Montserrat et al., 2012; Ponce, 2008).

\subsection{Factors polítics i estructurals. Les dificultats del sistema de protecció i educa-} tiu a l'hora de compensar el desavantatge dels infants i adolescents residents en CRAE.

En el procés de construcció del fracàs escolar hi ha certs elements interns del propi sistema educatiu que hi juguen un paper determinant (Fernández Enguita et al., 2010) $\mathrm{i}$, en el cas concret dels infants i adolescents residents en CRAE, també del sistema de protecció. Així, per acabar de comprendre la seva situació educativa, cal situar la mirada cap aquest nivell estructural de responsabilitat i preguntar-nos per què aquests sistemes no són capaços de compensar el desavantatge social i educatiu en què es troben els infants $i$ adolescents residents en CRAE, tal i com constaten les dades (Jackson i Cameron, 2014).

En primer lloc, cal tenir present que els infants residents en CRAE -i, en general, els infants i adolescents tutelats- no són considerats com un col-lectiu específic dins el context escolar i, per tant, no es tenen en compte les seves especificitats (Jackson i Cameron, 2014; Montserrat et al., 2012). Aquest fet, sumat al baix percentatge que representen dins el conjunt del sistema educatiu, difumina la visió de "col·lectiu" i fa que aquests casos es visquin com una qüestió interna de cada escola o, inclús, de cada aula, podent provocar un sentiment d'isolament i soledat per part del mestre/a, que sovint n'acaba esdevenint l'últim -i únic- responsable.

En segon lloc, el sistema de benestar i el sistema educatiu tendeixen a delegar responsabilitats l'un en l'altre i a no actuar conjuntament. Aquesta manca d'atenció, responsabilització, implicació, coordinació i col-laboració a tots els nivells d'ambdós sistemes ha estat analitzada i denunciada abastament per les investigadores del projecte YiPPEE, tant a nivell europeu com català, ja que és un impediment important per a l'avenç en la consecució d'èxit educatiu per part dels infants i adolescents residents en CRAE (Jackson i Cameron, 2014; Montserrat et al., 2015, 2012). 
En tercer lloc, hi ha una sèrie d'elements relacionats amb la "no-neutralitat" de l'escola i del sistema educatiu, que segueix els paràmetres de la "classe mitjana autòctona" (Bourdieu i Passeron, 1964), que xoquen frontalment amb les particularitats de la situació sociofamiliar i la trajectòria vital i escolar dels infants que resideixen en CRAE. Els alumnes que no responen a "l'ideal escolar" són vistos pels docents com a "diferents" i com un problema, fet que repercuteix en la seva vivència escolar i la generació de les seves pròpies expectatives i els va allunyant de la cultura escolar (Collet-Sabé et al., 2014).

Aquest procés "d'allunyament" és "recíproc": no només l'infant o adolescent es va allunyant progressivament del context escolar en un procés marcat pel desinterès i la dificultat que inclou retards, males notes, desatenció, indisciplina i absentisme (Fernández Enguita et al., 2010), sinó que l'escola també el va "apartant” a través de l'aplicació d'una sèrie de mesures de "diversificació" i mesures "correctives" de marcat to segregador tals com l'escolarització en escoles d'educació especial, suport fora de l'aula, grups flexibles basats en el comportament i rendiment acadèmic, i l'aplicació de mesures disciplinàries que inclouen, en un percentatge significativament major pels infants i adolescents de CRAE que per a la resta d'alumnes, l'expulsió (Connolly, 2012; Jackson i Cameron, 2014; Montserrat et al., 2012).

Per altra banda, tal i com està constatat abastament, cal tenir en compte la gran influència que tenen les expectatives inicials dels mestres en el rendiment i itinerari escolar dels alumnes (Rist, 1970; Tarabini, 2014). Aquestes estan fortament condicionades per l'origen social dels alumnes i parteixen del model "ideal" d'alumne que, segons el mestre, reuneix les característiques necessàries per assolir l'èxit acadèmic. De tal manera que l'infant i adolescent tutelat també pateix, en aquest sentit, una clara situació desfavorable en quant a la seva situació familiar ja que, no només prové d'una família d'entorns marginals, sinó que viu en un context residencial poc conegut i ple d'atribucions negatives per part dels mestres.

Sovint, les baixes expectatives dels mestre són compartides pels educadors/es del CRAE, professionals que tenen una gran influència sobre la trajectòria i orientació escolar dels infants i joves amb qui conviuen. Aquests tendeixen a veure les qüestions escolars més com un problema que com una oportunitat, supeditar-les a altres aspectes relacionats amb la conducta, la gestió emocional i les relacions familiars, i a prioritzar aspectes laborals i l'autosuficiència econòmica dels joves tenint com a horitzó el desinternament (Jackson i Cameron, 2014; Montserrat et al., 2015, 2012). 
Les expectatives no només condicionen el tracte i la relació que estableix l'adult amb l'infant, la manera d'organitzar la classe, l'atenció i suport que es dóna a cadascú, sinó també les expectatives que té l'infant i adolescent sobre ell mateix en l'àmbit escolar i la configuració de la seva "identitat escolar" i acaben tenint impacte directe sobre els resultats de l'alumne en forma del què s'anomena "efecte pigmalió" o "profecia autocomplerta" (Rosenthal i Jacobson, 1980).

En efecte, els diferents elements, entre ells les expectatives inicials del mestre i l'educador-cuidador, es van articulant i construint "l'experiència escolar" de l'alumne: una sèrie de vivències subjectives relacionades amb l'àmbit escolar que poden arribar a establir una diferència substancial entre alumnes marcant l'èxit o el fracàs escolar (Dubet i Martuccelli, 1998). Així, en funció de l'experiència escolar, podem trobar infants i adolescent pels quals l'escola és un entorn positiu, "normalitzador" i coincident amb el seu objectiu vital de superació personal / familiar i aquells pels quals és un espai hostil, ple de dificultats, que evidencia la seva situació familiar "diferent" i és una font de fracassos personals i socials.

\section{Consideracions finals. La necessitat de canviar de mirada i construir ambients educatius possibilitadors.}

Convertir els factors que s'exposen en el present article en possibilitadors d'èxit educatiu és una responsabilitat compartida per les instàncies polítiques, institucions i professionals dels sistemes educatiu i de protecció que es fan càrrec d'aquests infants i treballen pel seu benestar que cal situar a l'ordre del dia per tal que es converteixi en la oportunitat i factor de protecció que pot esdevenir.

La recerca ens mostra que actualment, lluny de compensar la situació de vulnerabilitat social que viuen els infants i adolescents residents en CRAE, el seu pas per l'educació formal i els seus itineraris educatius estan plens d'obstacles i dificultats i sovint acaben prematurament. De tal manera que l'èxit educatiu dels infants de CRAE encara està reduit a casos excepcionals, relacionats amb factors individuals que podem identificar amb la capacitat de resiliència de l'infant o adolescent. 
En efecte, entre els joves que han passat pel sistema de protecció i assoleixen un cert èxit en l'àmbit educatiu s'han pogut detectar una sèrie de característiques personals que tenen a veure amb habilitats socioemocionals i la capacitat de resiliència tals com l'autonomia, l'acceptació de les normes, la perseverança en el treball, la bona regulació emocional, habilitat de negociació i assertivitat, capacitat per establir vincles positius, determinació, autoconfiança i afany de superació, entre d'altres (Jackson i Cameron, 2014; Montserrat et al., 2012; Sala et al., 2009).

Aquestes investigacions recents, realitzades des de la perspectiva de la resiliència, ens permeten afirmar que els resultats acadèmics, les competències socioemocionals i la capacitat de resiliència són elements indissociables que es promouen mútuament essent, tots tres, factors de protecció clau per a la integració social futura dels infants i adolescents residents en CRAE (Jackson i Cameron, 2014; Montserrat et al., 2012; Sala et al., 2009). De tal manera que es fa evident la necessitat de situar la teoria i pràctica educativa des d'aquesta perspectiva i reivindicar un "canvi de mirada” envers els itineraris educatius dels infants i adolescents tutelats que, encara que puguin estar plens de dificultats, constitueixen una oportunitat vital de gran importància per trencar amb el cercle de marginalitat al qual estan immersos (Jackson i Cameron, 2014; Montserrat et al., 2012).

Com a procés dinàmic i variable, en el procés de desenvolupament de la capacitat de resiliència, el context familiar, social, escolar,... és clau (Grotberg i Morillo, 2006). Així, podem parlar de "famílies resilients" “escoles resilients" i, per què no, de "CRAEs resilients" i “educadors resilients”. Les característiques que fan que una institució, servei, professional,... esdevingui "resilient" es basen en l'adopció d'un model educatiu sistèmic, basat en les capacitats i recursos interns dels individus que reforça i genera opcions i oportunitats per les persones, es centra en els factors protectors i no de risc, i promou el "bon tracte" $\mathrm{i}$ el benestar a partir de vincles afectius positius (Barudy i Dantagnan, 2005; Vanistendael i Lecomte, 2002).

En aquest sentit, cal no menystenir els efectes positius que pot tenir el fet d'ésser un infant o adolescent tutelat (Forrester, 2008). I tenir present que si els emplaçaments són estables $\mathrm{i}$ adequats a les característiques i necessitats dels infants poden tenir un impacte positiu (Munro, 2011). Des d'aquesta perspectiva, els centres residencials i les escoles poden ser l'oportunitat de "resilir" dels infants i adolescents tutelats. Un context privilegiat on 
poder afavorir la seva capacitat de superar el desavantatge del qual parteixen posant més atenció a l'educació formal i no formal dels infants que resideixen en CRAE i a la seva inclusió social, i optimitzant els serveis i recursos que hi intervenen seguint els principis de la "discriminació positiva" (Bourdieu, 1997; Brenstein, 1970; Demeuse, Frandji, Gerger, i Rochex, s.d.).

En aquest sentit, les propostes del present article coincideixen plenament amb les que es deriven del projecte YiPPEE, compartint la tesi segons la qual la clau es troba en integrar la cura i l'educació en el dia a dia dels infants als centres i a les escoles. És a dir, oferir-los escoles que "cuiden" i centres que "eduquen":

"[..] for children to thrive and flourish, and realise their potential, and particulary where they have had very difficult early childhoods, they need to be cared for in school and educated at home. The Integration of care and education in daily life is key" (Jackson, Cameron, i Connelly, 2015, p.7).

És a dir, es necessiten centres residencials i professionals amb una gran qualitat educativa, que ofereixin ambients generadors d'oportunitats i estimulants a nivell intel-lectual, cultural i de participació social. A la vegada, calen escoles sensibles vers les dificultats personals que pot tenir un infant tutelat, amb recursos i valentia per generar "diferències" compensadores, prou flexibilitat per poder individualitzar processos d'aprenentatge i itineraris acadèmics i capacitat per saber-se ajudar per l'entorn i apostant per un treball sistèmic i col-laboratiu amb aquest. 


\section{Referències bibliogràfiques}

Bourdieu, P. (1997). Capital cultural, escuela y espacio social. Mèxic: siglo XXI.

Bravo, A., i Fernández, J. (2001). "Evaluación de la integración social en acogimiento residencial”. Psicothema, 13(2), 197-204.

Bravo, A., i Fernández, J. (2003). "Las redes de apoyo social de los adolescentes acogidos en residencias de protección: un análisis comparativo con población normativa”. Psicothema, 15(1), 136-142.

Brenstein, B. (1970). “A Critique of the Concept of «Compensatory Education»”. A: Rubinstein, D., i Stoneman, C. Education for Democracy. London: Penguin.

Casas, F. (2012). "La protecció dels infants i adolescents en situació de risc social i desemparament a Catalunya”. DOCS infancia Catalunya. UNICEF. [article en línia]. [Data de consulta: 1 de juliol de 2016].

Cebolla-Boado, H., Radl, J., i Salazar, L. (2014). “Aprendizaje y ciclo vital”. Colección estudios sociales, 39. Obra Social La Caixa. [publicació en línia]. [Data de consulta: 1 de juliol de 2016].

Collet-Sabé, J., Besalú, X., Feu, J., i Tort, A. (2014). Escuelas, familias y resultados académicos: un nuevo modelo de análisis de las relaciones entre docentes y progenitores para el éxito de todo el alumnado. Profesorado: Revista de curriculum y formación del profesorado, 18(2), 7-33.

Connolly, J. (2012). “They never give up on you. The Children's Commissioner's Inquiry into School Exclusions". Education Review, 24(2).

Curran, M., i Tarabini, A. (2013). "Políticas de lucha contra el abandono escolar en España: hacia la definición de un modelo teórico-metodológico". Revista de la Asociación de Sociología de la Educación, 5(3), 91-99. 
Demeuse, M., Frandji, D., Gerger, D., i Rochex, I. (s.d.). Les politiques d'éducation prioritarie en Europe. Lió: ENS Éditions.

Dubet, F., i Martuccelli, D. (1998). En la escuela: sociología de la experiencia escolar. Madrid: Losada.

Eurostat - Tables, Graphs and Maps Interface (TGM). http://ec.europa.eu/eurostat/ tgm/refreshTableAction.do?tab=table\&plugin=1\&pcode=tps00066\&language $=$ en [Data de consulta: 26 de juliol de 2015].

Fernández, J. (2003). “Acogimiento residencial: ¿innovación o resignación?” Infancia y aprendizaje, 26(3), 365-379.

Fernández, J., Alvarez-Baz, E., i Bravo, A. (2003). "Evaluación de resultados a largo plazo en acogimiento residencial de protección a la infancia”. Infancia y Aprendizaje, 26(2), 235-249.

Fernández, J., i Fuertes, J. (2005). El acogimiento residencial en la protección a la infancia. Madrid: ediciones pirámide.

Fernández Enguita, M., Mena Martínez, L., i Riviere Gómez, J. (2010). Fracaso y abandono escolar en España. Colección estudios sociales, 29. Obra Social La Caixa [publicació en línia]. [Data de consulta: 13 de juny de 2015].

Forrester, D. (2008). "Is the care system failing children?". The Political Quarterly, 79(2), 206-211.

Funes, J. (2008). El lugar de la infancia. Criterios para ocuparse de los niños y niñas hoy. Barcelona: Graó.

Jackson, S., i Cameron, C. (2014). Improving Access to Further and Higher Education for Young People in Public Care: European Policy and Practice. London and Philadelphia: Jessica Kingsley Publishers. 
Jackson, S., Cameron, C., i Connelly, G. (2015). Educating children and young people in care. Learning placements and caring schools. London and Philadelphia: Jessica Kingsley Publishers.

Mapa de Serveis Socials de Catalunya. Actualització de dades bàsiques 2014. Departament de Benestar Social i Família. Generalitat de Catalunya. http://benestar. gencat.cat/ca/ambits_tematics/serveis_socials/estadistiques/mapa_de_serveis_socials_de_catalunya/mapa-de-serveis-socials-de-catalunya--actualitzacio-de-dades-basiques-2014/ [Data de consulta: 11 d'abril de 2015].

Martín, E., Muñoz, M. D. C., Rodríguez, T., i Pérez, Y. (2008). “De la residencia a la escuela: la integración social de los menores en acogimiento residencial con el grupo de iguales en el contexto escolar". Psicothema, 20(3), 376-382.

Montserrat, C., Casas, F., i Baena, M. (2015). L'educació dels infants i adolescents en el sistema de protecció. Un problema o una oportunitat? Girona: IRQV i Documenta Universitaria.

Montserrat, C., Casas, F., Casas, L., i Baena, M. (2013). “La situació escolar dels adolescents nacuts entre els anys 1997 i 2001 acollits en centre residencial, família extensa o aliena a Catalunya. Curs escolar 2012-2013”. Institut de Recerca sobre la Qualitat de Vida, Universitat de Girona. [publicació en línia]. [Data de consulta: 10 de maig de 2015].

Montserrat, C., Casas, F., Malo, S., i Bertran, I. (2012). Els itineraris educatius dels joves extutelats. Col-lecció infancia i adolescència, 6. Generalitat de Catalunya, Departament de Benestar i Família.

Munro, E. (2011). The Munro review of child protection: Final report. A child-centred approach. The Stationery Office.

Palacios, J. (2003). “Instituciones para niños:¿protección o riesgo?”. Infancia y aprendizaje, 26(3), 353-363. 
Passeron, J.C. i Bourdieu, P. (1964). Les héritiers: les étudiants et la culture. Paris: Éditions de Minuit.

Rist, R. (1970). "Student social class and teacher expectations: The self-fulfilling prophecy in ghetto education". Harvard educational review, 40(3), 411-451.

Rosenthal, R., i Jacobson, L. (1980). "Pigmalión en el aula”. A: N. Gluz, G. Kantarovich, i C. Kaplan. La escuela: una segunda oportunidad frente a la exclusión. Buenos Aires: Novedades Educativas.

Sala, J., Jariot, M., Villalba, A., i Rodríguez, M. (2009). "Analysis of factors involved in the social inclusion process of young people fostered in residential care institutions". Children and Youth Services Review, 31(12), 1251-1257.

Secretaria de Joventut. (2008). "Vulnerabilitat dels joves davant la crisi". Departament d'Acció Social i Ciutadania. Generalitat de Catalunya. [publicació en línia]. [Data de consulta: 25 de juliol de 2015].

Sinclair, I., Gibbs, I., i Wilson, K. (2004). Foster Carers: Why they stay and why they leave. London: Jessica Kingsley Publishers.

Síndic de Greuges. (2009, juny). "La protecció de la infancia en situació d'alt risc social a Catalunya”. Síndic. Informe extraordinari.[publicació en línia]. [Data de consulta: 7 de juliol de 2016].

Tarabini, A. (2014). Classe social, expectatives docents i èxit educatiu: una tríada indissociable. A: Capsada, Q. (coord). Com les notes condicionen les expectatives de l'alumnat. Barcelona: Fundació Jaume Bofill, pp. 61-72.

Torralba, J. M. (2006). "Els infants en els centres residencials d'acció educativa: protegits o estigmatitzats". Generalitat de Catalunya, Departament de Benestar i Família. [publicació en línia]. [Data de consulta: 13 d'abril de 2015]. 
Xedagogia i Treball Social

Revista de Ciències Socials Aplicades

Edita: Universitat de Girona

Disseny i maquetació: info@clam.cat · 647427732

Dipòsit Legal: GI.904-2010

ISSN: 2013-9063 